\title{
From ecological opportunism to multi-cropping: mapping food globalisation in prehistory
}

Xinyi Liu ${ }^{*}$, Penelope J. Jones², Giedre Motuzaite Matuzeviciute ${ }^{3}$, Harriet V. Hunt², Diane L. Lister ${ }^{2}$, Ting An ${ }^{4}$, Natalia Przelomska ${ }^{5}$, , Catherine J. Kneale², Zhijun Zhao ${ }^{7}$ and Martin K. Jones²*

${ }^{1}$ Department of Anthropology, Washington University in St. Louis, USA, ${ }^{2}$ McDonald Institute for Archaeological Research, University of Cambridge, Cambridge, UK, ${ }^{3}$ Department of City Research, Lithuanian Institute of History, Vilnius, Lithuania, ${ }^{4}$ Department of Cultural Heritage and Museology, Zhejiang University, Hangzhou, China, ${ }^{5}$ Department of Anthropology, National Museum of Natural History, Smithsonian Institution, Washington D.C., USA, ${ }^{6}$ Smithsonian's National Zoo \& Conservation Biology Institute, National Zoological Park, Washington D.C., USA, ${ }^{7}$ Institute of Archaeology, Chinese Academy of Social Sciences, Beijing, China.

*email: liuxinyi@wustl.edu, mkj12@cam.ac.uk

Citation: Liu, X., Jones, P.J., Motuzaite Matuzeviviute, G., Hunt, H.V., Lister, D.L., An, T., Przelomska, N., Kneale, C.J., Zhao, Z., Jones, M.K., 2019. From ecological opportunism to multi-cropping: mapping food globalisation in prehistory. Quaternary Science Reviews 206, 21-28. 


\begin{abstract}
Many of today's major food crops are distributed worldwide. While much of this 'food globalisation' has resulted from modern trade networks, it has its roots in prehistory. In this paper, we examine cereal crops that moved long distances across the Old World between 5000 and 1500 BC. Drawing together recent archaeological evidence, we are now able to construct a new chronology and biogeography of prehistoric food globalisation. Here we rationalize the evidence for this process within three successive episodes: pre-5000 BC, between 5000 and $2500 \mathrm{BC}$, and between 2500 and 1500 BC. Each episode can be characterized by distinct biogeographical patterns, social drivers of the crop movements, and ecological constraints upon the crop plants. By $1500 \mathrm{BC}$, this process of food globalisation had brought together previously isolated agricultural systems, to constitute a new kind of agriculture in which the bringing together of local and exotic crops enables a new form of intensification.
\end{abstract}

\title{
Key words
}

anthropocene; paleogeography; global; archaeobotany; food globalisation in prehistory; millet; wheat and barley; rice; sorghum

\section{Introduction}


Since Theodore Levitt (1983) brought the term 'globalisation' to economic studies, it has been employed in different ways in different fields (e.g. Held et al., 1999; James, 2005; Steger and James, 2013). Here, we return to Levitt's original usage, to describe the phenomenon of the same resources being consumed across many different cultures in different parts of the world. Levitt's interest was in the modern era and such items as cigarettes, digital watches and Coca-Cola. Our interest in is a much deeper history and the world's many staple crops.

The trans-regional movement of a number of these crops occurred within a series of transformative processes of food globalisation, each of substantial magnitude, but separated in time. The 'Columbian Exchange' involved the transfer of crops between the New World and the Old in the centuries post-dating 1492 AD (Crosby, 2003). Another example is the 'Islamic Agricultural Revolution', which transformed the global agricultural system between the $8^{\text {th }}$ to $13^{\text {th }}$ Century AD (Watson, 1983). Several millennia prior to these, a 'Trans-Eurasian Exchange' took place and this has been discussed by various archaeologists. It involved the exchange of crops between the eastern and western parts of Eurasia and also north Africa (Fuller et al., 2011a; Jones et al., 2016b; Jones et al., 2011b). This earlier exchange, elements of which are first discerned prior to $5000 \mathrm{BC}$ and which attains a very complete form around $1500 \mathrm{BC}$, brought previously isolated cultivation systems, human populations, and ideas from different regions into contact with each other, across the entangled network of the prehistoric Old World. 
Early conversations on the ancient interactions between east and west of Eurasia focus on issues such as language, urbanization, pastoralism and analyses of material culture (Bellwood and Renfrew, 2002; Boyle et al., 2002; Wilkinson et al., 2011). Sherratt (2006) , for example, observed that two cultural traditions of the East and the West, separated by the Pamir Mountains in the centre of the Eurasian Continent, were characterized by their use of ornamental stones in the contrasting colors of blue and green, that is lazurite and jade. This separation began to break down around $1500 \mathrm{BC}$, through the dispersal of various material traditions across the region, and especially metallurgical technologies (Mei, 2003; Sherratt, 2006). Recent discussions have moved beyond the evidence of material culture alone, to include that of crop plant remains, and put forward the case that the middle of the second millennium BC marks not the threshold, but rather the culmination of an episode of food globalisation in prehistory (Jones et al., 2011b).

In recent years, the gathering of new archaeobotanical evidence from across Eurasia has intensified, allowing a richer and more detailed picture to emerge (e.g. Barton and An, 2014; Betts et al., 2014; Bogaard, 2004; Boivin et al., 2014; Chen et al., 2015; Colledge and Conolly, 2007; Frachetti, 2012; Fuller et al., 2011a; Fuller et al., 2010; Hunt et al., 2008; Jones et al., 2016a; Lightfoot et al., 2013; Lister and Jones, 2012; Liu and Jones, 2014; Miller et al., 2016; Motuzaite Matuzeviciute et al., 2013; Spengler et al., 2014; Stevens et al., 2016; van der Veen, 2010; Zhao, 2011; Zohary et al., 2012). In this paper, we shift the focus to the evidence of the crop plants that moved, and work towards a new framework of chronology and biogeography. On 
the basis of the chronology and biogeography of crop movement, we organize the evidence into three episodes. Before $5000 \mathrm{BC}$, crop dispersals are generally to neighboring regions that are broadly compatible in terms of climate and seasonality, for example, in the East the monsoonal belt, and in the West, the mid-latitude belt subject to westerlies. Between 5000 and $2500 \mathrm{BC}$, various crops extended to the edges of those weather systems contained within and separated by the principal mountain systems and in particular, those associated with the Tibetan Plateau and the Tianshan Mountains. Between 2500 and 1500 BC, a number of crops crossed those boundaries. That crossing of boundaries brought well-established local and recently introduced exotic crops together, both of which had to adapt to varied environments and a new type of human-dominated ecological niche. This in turn allowed for the establishment of a new kind of Old World agriculture, with a focus upon multi cropping (Jones et al., 2016b).

\section{Scope and materials}

At the core of this process of globalisation is the movement of several principal staples. Free threshing wheat (Triticum cf. aestivum) and barley (Hordeum vulgare) moved from southwest Asia to Europe, India and China, while broomcorn millet (Panicum miliaceum) and foxtail millet (Setaria italica) moved in the other direction: from China to the West, via Central and South Asia; rice (Oryza sativa) travelled across East, South and Southeast Asia; and African millets (Pennisetum glaucum and Eleusine coracana) and sorghum (Sorghum bicolor) moved across sub-Saharan 
regions and ultimately across the Indian Ocean to South Asia. Other economic important plant taxa, including pulses and fruits, as well as domesticated animals, also spanned across the Old World in various episodes of prehistory.

Prior to $5000 \mathrm{BC}$, the cropping systems that had come into being around distinct centres of domestication remained relatively isolated from each other. By c. 1500 $\mathrm{BC}$, this situation had changed dramatically, with numerous crops grown all over the Eurasia and in parts of Africa. The rapidly amassing body of archaeobotanical evidence has here been rationalized into three distinct periods, illustrated in maps in Figures 2 to 4. Locations of representative key sites are indicated in Figure 1. Site information and associated archaeobotanical data are detailed in Supplementary Table S1. This table is drawn from a number of key reviews of crop evidence for different sectors of the Old World. The European and West Asian sites included in this study are largely derived from the fourth edition of Domestication of Plants in the Old World (Zohary et al., 2012), and Colledge and Conolly's (2007) edited volume. The Central Asian sites discussed incorporate Spengler (2015), Spengler et al. (2014; 2016) and Motuzaite Matuzevicute and colleagues' (2018) recent reviews, among other sources. The South Asian data draws together various sources of evidence, including Fuller (2006; 2011a), Fuller et al. (2008), Weber (1998; 2003), Stevens et al. (2016) and Pokharia et al. (2014), among others. The East Asian list of sites has been sourced from reviews by Zhao (2010c; 2011), Liu et al. (2015), Ren et al. (2017), Barton et al. (2014), Dong et al. (2017) and d'Alpoim Guedes et al. (2014; 2013), among others. We have sourced the original publications for each site. 


\section{What is moving and to where?}

\subsection{Pre-5000 BC (Figure 2)}

The dispersal of the southwest Asian crops in the millennia preceding $5000 \mathrm{BC}$ was more extensive than that of the East Asian crops. A number of wheat and barley taxa had spread from the southwest Asian Fertile Crescent westwards across central and eastern Europe and along northern regions of the Mediterranean (Colledge and Conolly, 2007; Zohary et al., 2012). To the east, various types of wheat and barley are recorded in Turkmenistan and Pakistan before 5000 BC (Harris, 2010; Meadow, 1996; Petrie, 2015). In China, broomcorn and foxtail millet were first cultivated along a series of foothill locations adjacent to the eastern edge of the Loess Plateau, around (and probably prior to) 6000 BC (Liu et al., 2015; Liu et al., 2009; Yang et al., 2012). By 5000 BC, these millets are also found in sites in the Wei River valley (Bestel et al., 2017; Liu et al., 2004), and in the eastern province of Shandong (Crawford et al., 2006). The middle and lower reaches of the Yangtze have been established as the centres of Asian rice domestication (Fuller et al., 2009; Gross and Zhao, 2013), although different Oryza spp. were independently domesticated in West Africa and Amazonia, respectively, during the middle to late Holocene (Hilbert et al., 2017). By 5000 BC, Asian rice (Oryza sativa) remains are reported in the reaches of the Huai and the lower Yellow rivers (Bestel et al., 2017; Crawford et al., 
2006; Zhao, 2010b). By 5000 BC, a separate center of possible utilization of wild rice has been documented in the Ganges region (Fuller, 2006; Tewari et al., 2008).

\section{$3.25000-2500$ BC (Figure 3)}

Between 5000 and $2500 \mathrm{BC}$, wheat and barley cultivation expanded into eastern Central Asia and South Asia. While both hulled and naked forms of wheat and barley are reported from South Asia, in Central Asia, the expansion of these species seems restricted to free-threshing/naked forms (Motuzaite Matuzeviciute et al., 2018; Spengler 2015). By 2500 BC, these crops are present in eastern Kazakhstan (Doumani et al., 2015; Frachetti et al., 2010), the southern Indus region and in the upper Ganges (Fuller, 2011a; Weber, 1999). A recent study reports that wheat grains recovered from the Altai Mountains are directly dated to c. $3000-1500 \mathrm{cal}$. BC (Yu et al., 2018). During the same period, morphologically domesticated sorghum is found in eastern Sudan (dated to the fourth millennium BC) (Winchell et al., 2017).

The same period sees the further expansion of millets and rice in East Asia. Broomcorn millet is reported from Primorye in the Russian Far East at c. 3000 BC (Sergusheva, 2006). Foxtail millet cultivation reached Taiwan in the late third millennium BC (Tsang, 2012), and both millets are reported in eastern Qinghai and Gansu c. 3000 BC (Chen et al., 2015; Dong et al., 2017; Jia et al., 2012). From there the cultivation of these crops moved southward and reached the mountainous region of western Sichuan by c. 2500 BC (Zhao and Chen, 2011). Rice cultivation 
reached the full range of the Yangtze and Yellow River catchments, as well as Guangxi and Taiwan (Fuller et al., 2010; Tsang, 2012; Zhao, 2010a). In India, evidence for rice cultivation appears from c. $2500 \mathrm{BC}$ in both the Indus and the Ganges, although clear morphological evidence of domesticated spikelet, in the form of non-shattering panicles, is not seen until the next episode (Fuller et al., 2011b; Saraswat, 2004).

\subsection{0 - 1500 BC (Figure 4)}

Between 2500 and 1500 BC, the Fertile Crescent crops wheat and barley were introduced to eastern China and southern India. Wheat grains in Shandong have been directly dated to between c. 2500 and 2000 cal. BC (Jin et al., 2008; Long et al., 2018). This raises the question of whether wheat was first introduced to China via a maritime route (Zhao, 2009). More substantial movements of wheat and barley took place after $2000 \mathrm{BC}$ across land (Liu et al., 2016a). The spreads of free threshing wheat and naked barley into China appear to be distinct in both space and time (Liu et al., 2017a), via several possible different routes (Lister et al., 2018). These crops appeared in central China during the second and the first millennium BC, respectively (though note the early dates of wheat in eastern province of Shandong discussed above) (Liu et al., 2017a). Wheat cultivation moved to central China along a series of mountain corridors to the north of the Tibetan Plateau. Barley, on the other hand, could have spread into China from South Asia via Tibet, and this model best fits the available radiocarbon dates. 
Broomcorn and foxtail millet spread beyond China, westwards into Central Asia and southwestwards into South Asia (Pokharia et al., 2014; Spengler et al., 2014).

Broomcorn millet is reported from eastern Kazakhstan in the late third millennium BC. Foxtail millet appeared in the same region about a millennium later c. $1500 \mathrm{BC}$ (Spengler et al., 2014). During the second millennium BC, broomcorn millet appeared in Afghanistan, Turkmenistan, Turkey and Greece (Miller et al., 2016; Spengler 2015; Valamoti, 2013; Willcox, 1991). The issue of early broomcorn millet in Europe is not yet fully resolved. The oldest direct dates for broomcorn millet grains in Europe are c. 1600 BC in Hungary (Motuzaite Matuzeviciute et al., 2013). A series of much older, indirect dates of millet remains have been called into question (and could be intrusions of younger seeds into Neolithic layers) (Hunt et al., 2008; Jones, 2004; Liu et al., 2018b; Motuzaite Matuzeviciute et al., 2013). There is also a series of early indirect dates from grain impressions in Neolithic pottery from eastern Europe. These are reliant on the security of identification of casts from impressions, which were largely conducted and published prior to the widespread use in archaeobotany of electron microscopy. Recent study draws attention to features that could be useful for future SEM examination (An et al., 2018). In South Asia, both broomcorn and foxtail millet are common in late Harappan sites at least from the early second millennium BC (Pokharia et al., 2014; Stevens et al., 2016; Weber, 1998). Broomcorn millet is also reported in Yemen dated to the mid-second millennium $\mathrm{BC}$ and there is evidence for its spread into Sudan before the midsecond millennium BC (Boivin and Fuller, 2009b; Fuller et al., 2011a). In Southeast 
Asia, foxtail millet is reported from Thailand at around c. 2000 BC (Weber et al., 2010).

By this period, rice cultivation was fully developed in East, South and Southeast Asia (Fuller, 2011b; Fuller et al., 2010; Zhao, 2010a). There is clear evidence of domesticated rice across northern India at least from 2000 BC (Bates et al., 2016; Fuller, 2006). Genetic evidence indicates substantial hybridization between japonica and indica forms during the dispersal of Asian rice (McNally et al., 2009; Sang and Ge, 2007; Vaughan et al., 2008). Fuller et al. (2010) suggest that hybridization initially occurred during the centuries after $2000 \mathrm{BC}$ when domesticated japonica rice diffused from China to South Asia. African millets and sorghum appear in Indus sites during this period, in the context of a network of resource movement across the Indian Ocean (Boivin et al., 2014; Boivin and Fuller, 2009a; Fuller et al., 2011a).

\section{Discussion}

Drivers of the food globalisation process include seasonal, culinary and cultural differences among different sectors of the Old World. We have considered elsewhere the context in which agricultural/dietary innovations arose and what agents were involved (Liu and Jones, 2014; Liu et al., 2014; Liu et al., 2016a; Liu et al., 2018a; Liu et al., 2016b; Liu et al., 2017b). These studies emphasize the role played by the primary agents of agricultural production, the ordinary farming communities, and elucidate that the cultural and culinary choices facilitate not only 
the adoption of some crops but also the rejection of others. Given the biogeographic focus of this paper, nonetheless, the following discussion primarily considers the topographical and environmental context of each movement. The movement of Neolithic and Early Bronze Age communities in the Old World was constrained by a series of major topographical features. Prominent among those features were the Tibetan Plateau and the mountain ranges of Central Asia, separating the east from the west, and the north from the south. The Himalayan uplift and its associated plateau separate the warm, semitropical and tropical lowlands of South Asia from the seasonal and arid temperate regions of Central Asia. It also separates the monsoonal regions of East Asia from non-monsoonal southwest Asia. Once pathways of movement and communication around deserts and mountains had been established, crops could be moved extensively from their regions of origin.

\subsection{Pre-5000 BC: Ecological opportunism}

Not only was the distribution of early farming sites restricted, it was also topographically selective. In comparison with cultivation today, farmers utilized a smaller fraction of the land. The earliest farming settlements in southwest Asia and China appeared along elevated locations at the edge of river catchments, sometimes at a considerable distance from the main river channel. A recurrent theme in both regions is that the earliest farming sites were situated along hilly flanks (Braidwood et al., 1969; Liu et al., 2009; Ren et al., 2016). The choice of sites appears to be associated with certain environments and situations: foothills, alluvial fans and lake 
edges with high groundwater levels are repeatedly chosen by early Holocene farmers/foragers in both the Near East and in China. We can infer from these site locations that early agriculturalists occupied a narrow zone of maximum productivity, in an essentially small-scale though locally intensive system of cultivation (Liu et al., 2009; Sherratt, 2005; Vita-Finzi, 1969).

Crop expansion in this period is everywhere constrained within these topographic locales. We may understand such expansions in the context of increasing needs for connectivity, such as the seeking of new lands, marriage partners and other resources. Before $5000 \mathrm{BC}$, the association of settlements with foothills is observed in both the west, along the 'Hilly Flanks' of southwest Asia towards the Iranian Plateau, and in the east, along the edge of a series of low mountains east of the Loess Plateau.

\subsection{0-2500 BC: The filling of familiar environmental niches}

Between 5000 and $2500 \mathrm{BC}$, three agricultural systems (characterized by: wheat and barley; broomcorn and foxtail millets; and Asian rice) expanded substantially. However the distribution of sites remained relatively ecologically constrained: as in the previous period, sites were located along the chains of foothills along various river catchments that connect with the Central Eurasian mountain system (Frachetti, 2012). The preferred sites were often at nodal points on routes of interregional contact, where populations might congregate for social engagement, the 
exchange of goods or seasonal herding (Frachetti et al., 2017). In other words, during this episode, a series of choices of environmental niches favoured by earlier generations of farmers are rolled out across similar conditions in other parts of the Old World.

\subsection{0-1500 BC: Movement, disassembly and reassembly}

Between 2500 and $1500 \mathrm{BC}$ the ecological and geographical boundaries so constraining in previous periods were crossed. In this third phase, the predominantly winter sown crops wheat and barley spread to east China, where the indigenous crops such as broomcorn, foxtail millet and rice are mostly sown in the spring and summer. Conversely, the predominantly spring sown crops broomcorn and foxtail millet spread to southwest Asia and Europe, where the indigenous cereals are originally winter sown. Recent research indicates that the adaptation of crops to novel seasonal conditions may have played a role in facilitating the expansion of particular crops, for example wheat and barley into the northern latitudes of Europe and higher altitudes of Asia (Jones et al., 2012; Jones et al., 2011a; Jones et al., 2016a; Liu et al., 2017a). These crop translocations brought their cultivation into different thermal and hydrological contexts, requiring a different mode of engagement between farming cycles and crops with different seasonalities, in sometimes challenging environments. 
While consideration of a map of Eurasia primarily draws our attention to the possibilities of movement across horizontal space, the prehistoric communities with both indigenous and exotic crops would have been acutely aware of the vertical dimension of their journeys, for example towards the high altitudes of the Himalayan uplift. Beneath them were the lowlands, characterized by hydrological extremes, from large un-tamed rivers to barren deserts. Above these farmers were the highlands, characterized by high winds, low temperatures and bare rock. In between these extremes were the habitable altitudes, with sufficient soil depth, and a year-round flow of water within modest, manageable streams. As they moved into new landscapes, they would have been sometimes attracted to higher altitudes to reach a more reliable source of water, and at other times descended to warmer conditions at lower altitudes.

During these movements, we see some of the familiar crop clusters unpacked, with individual crops displaying distinct patterns of movement. The eastern expansion of wheat and barley are distinct in both time and space, as are possibly the movements of broomcorn and foxtail millet westward. These patterns reflect a range of choices that different communities made, sometimes driven by ecological expediency in novel environments, sometimes by culinary conservatism (e.g. Fuller and Castillo, 2016; Liu et al., 2016a; Liu et al., 2016b). Such unpacking and separate movement was followed by reassembly into novel combinations and clusters. These crops with different biogeographic and ecological histories, could be grown in different seasons, enabling multi-cropping and the fuller use of the agricultural year. These novel 
attributes in turn facilitated the full use of the lowlands beneath them. If the large rivers could be managed, controlled and made safe, then we suggest that their larger volumes of water could have been used to meet the greater demands of novel agricultural systems, comprising the cultivation of both local and exotic cereals.

Such a bringing together of local and exotic crops, that came together to form various multicropping systems around the Old World, is documented not only in the archaeobotanical evidence of this period, but also in the early textual records from China and Mesopotamia (e.g. Postgate, 1984; Qiu, 1989; Waetzoldt, 1985). After $1500 \mathrm{BC}$, the previously isolated Eurasian agricultural systems had established contact, dissembled and reassembled, to constitute a series of new forms of agriculture. Social changes that took place in central China, the Indus, Mesopotamia and Mediterranean in this period may be understood in this context.

\section{Conclusion}

In the Neolithic and Early Bronze Age, the various Eurasian and African farming centres were relatively separate from each other, and generally exploited local resources. After $1500 \mathrm{BC}$, previously isolated agricultural systems were brought together, dissembled and reassembled, to constitute a new kind of agriculture with the possibility of multiple cropping. In previous discussions on the cultural and social drivers underlying food globalisation in prehistory, a contrast has been drawn between the perpetual needs of the poor with the more ephemeral cultural choices 
of the powerful (Liu and Jones, 2014). The fact that the globalisation process spanned several millennia, while it does not exclude a cultural choice as a trigger, indicates that more lengthy drivers had sustained the gradual dispersals of staple crops discussed in this paper. In this paper we argue this process can be understood in the context of three successive episodes: before $5000 \mathrm{BC}$, between 5000 and 2500 BC, and between 2500 and 1500 BC.

1. Before $5000 \mathrm{BC}$, farming communities living in different parts of Eurasia took advantage of local environmental and biotic resources, utilizing foothill, alluvial and catchment locations.

2. Between 5000 and $2500 \mathrm{BC}$, the translocation of various cereal crops and associated agricultural knowledge spanned considerable distances. These translocations, nonetheless, remained ecologically and geographically constrained. Prominent in those geographical constraints were the Tibetan Plateau and the Asian monsoons, separating the east from the west, and the north from the south.

3. Between 2500 and 1500 BC, a number of crops crossed significant geographical boundaries. For example, the Near Eastern crops wheat and barley were introduced into India and China, and the Chinese crops broomcorn and foxtail millet appeared in sites in Central Asia and Europe during the same period. Each translocation brought crop cultivation to novel thermal and hydrologic contexts, with profound consequences for subsequent modes of agricultural production. 


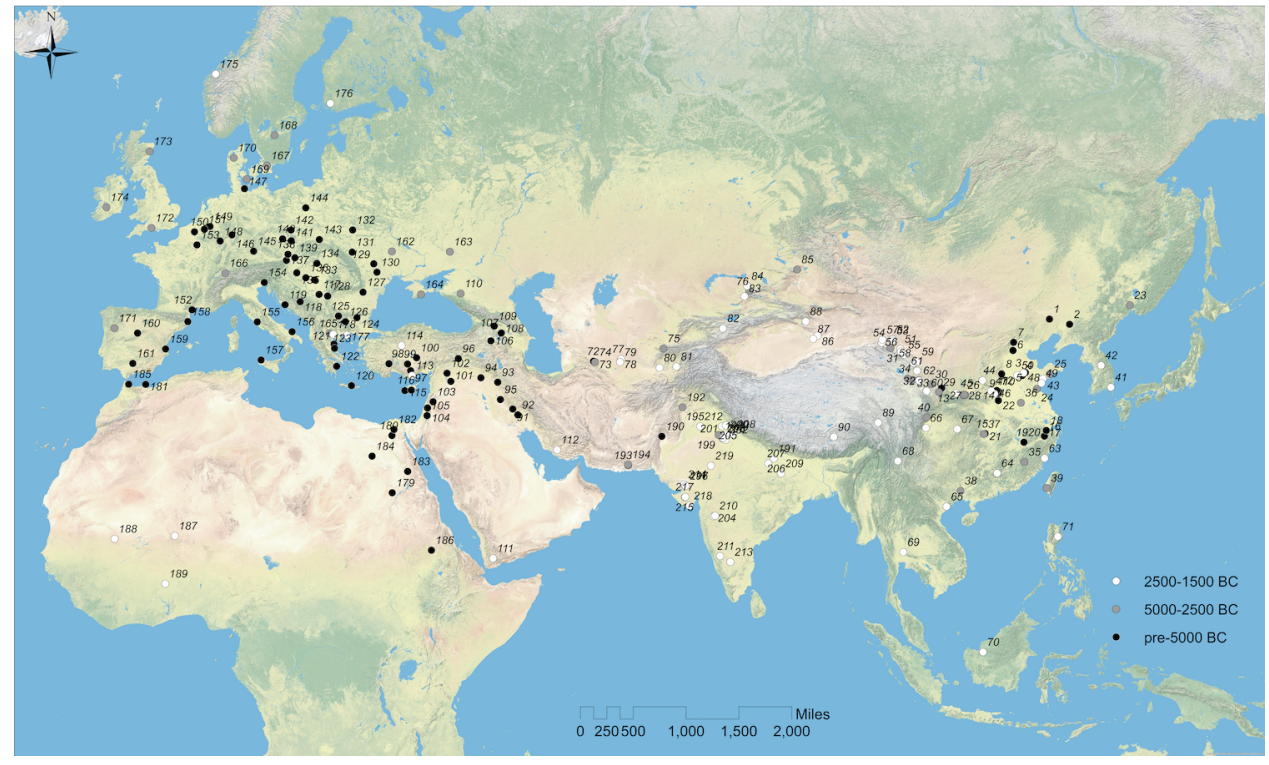

Figure 1 Locations of representative key sites with early evidence for domestication and translocation of wheat and barley, broomcorn millet, foxtail millet, rice, sorghum and African millets (all maps are generated by ArcMap v. 10.2). Sites information is detailed in supplementary Table S1. Black circles indicate sites older than 5000 BC; grey circles indicate archaeological sites dated between 5000 and 2500 BC; white circles indicate sites dated between 2500 and 1500 BC.

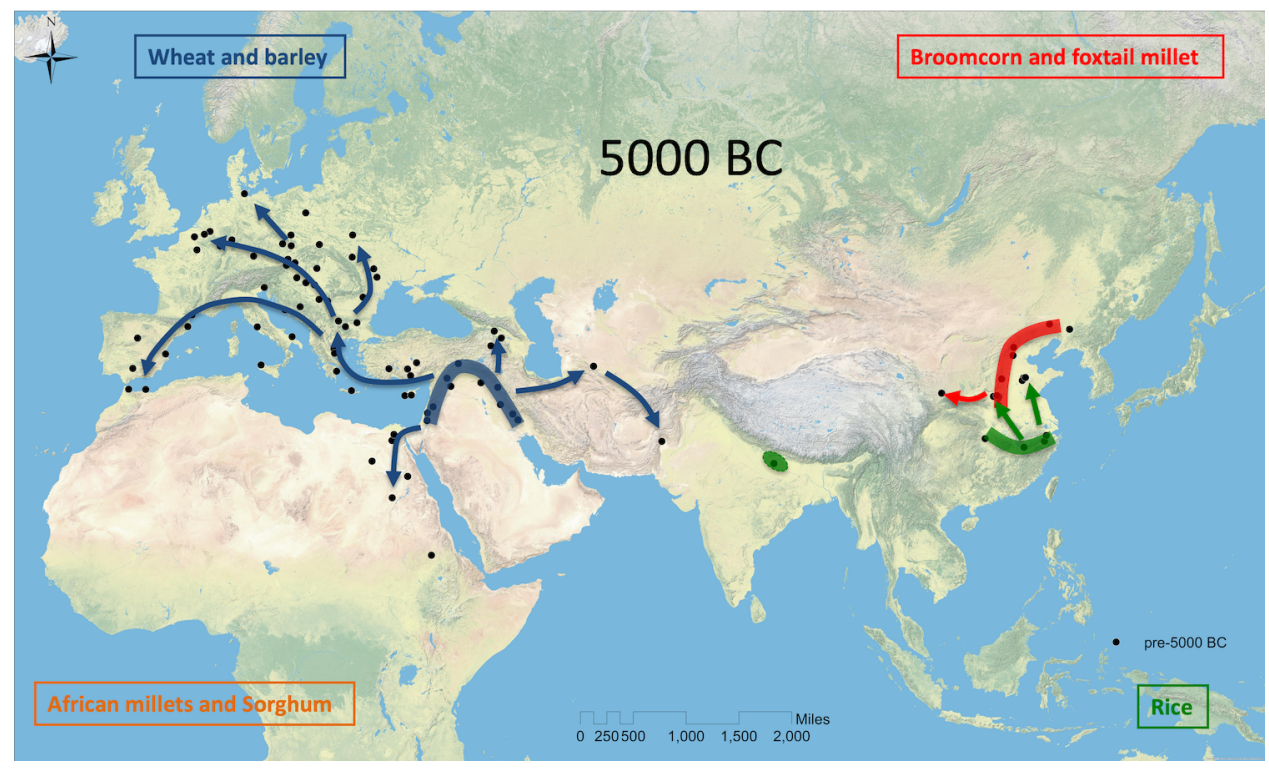


Figure 2 Map showing hypothesized dispersals of major cereal crops by 5000 BC.

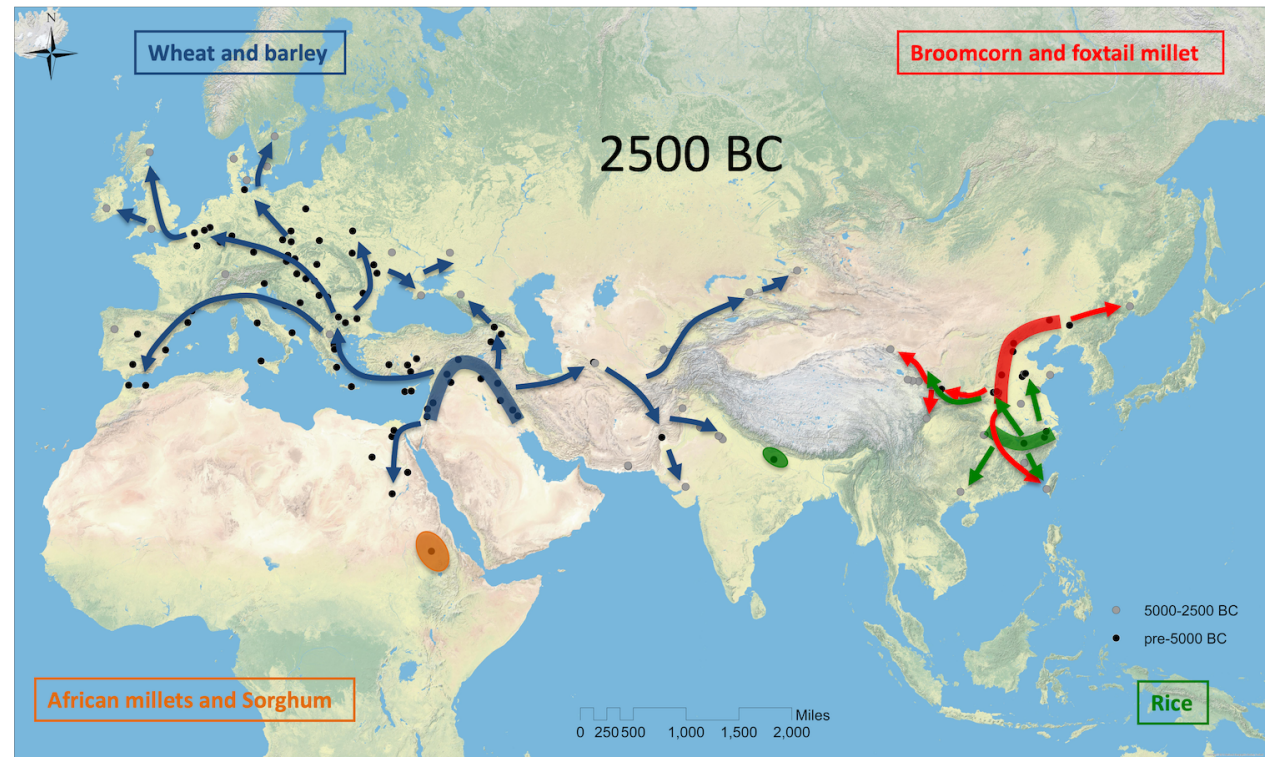

Figure 3 Map showing hypothesized dispersals of major cereal crops by 2500 BC.

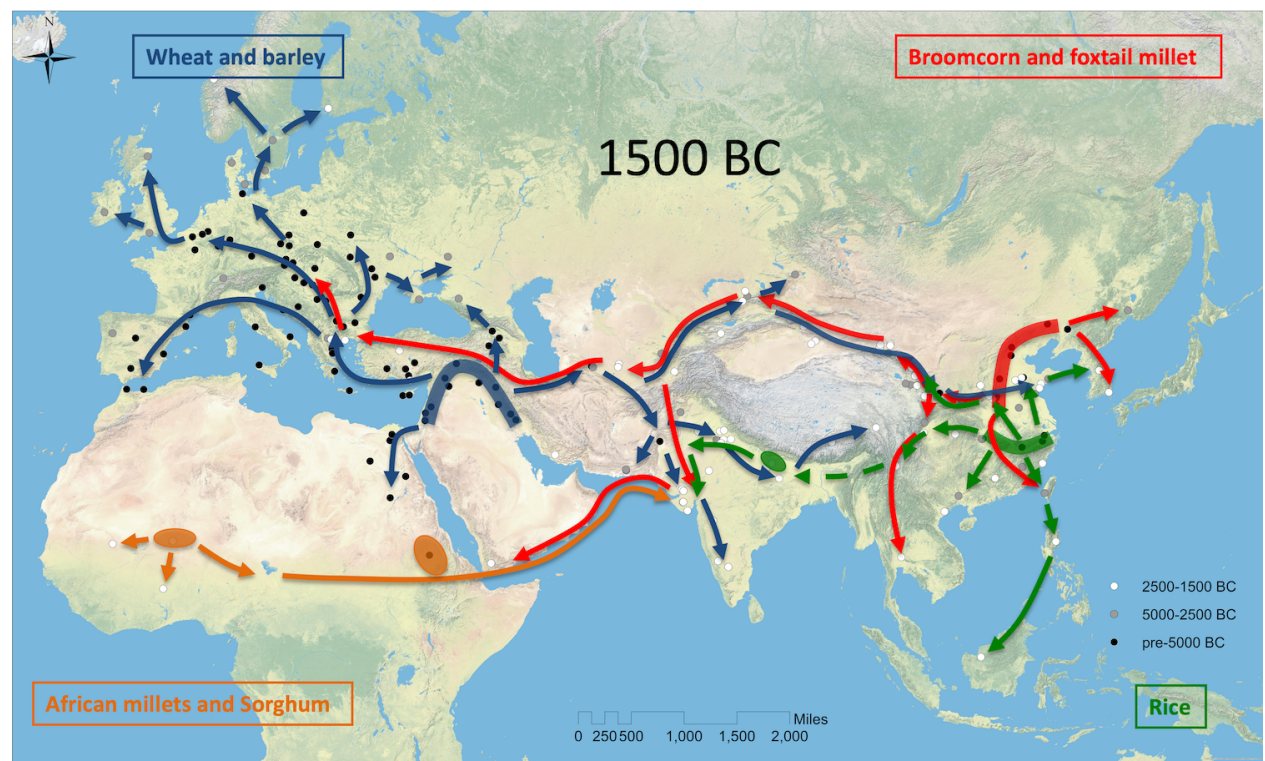

Figure 4 Map showing hypothesized dispersals of major cereal crops by $1500 \mathrm{BC}$.

Solid line: parsimonious inference from botanical evidence from dated archaeological contexts (the density of which varies greatly across Eurasia). Broken line: hypothetical hybridization occurring during rice dispersal. 


\section{Data availability}

All data analysed during this study are included in this manuscript and its supplementary information files.

\section{Acknowledgements}

The authors are grateful to the European Research Council, under grant 249642, "Food Globalisation in Prehistory" (FOGLIP, PI: M. K. Jones); the Leverhulme Trust, under grant f/09717/C, "Pioneers of Pan-Asian Contact"(PPAC, PI: M. K. Jones); the National Science Foundation, under grant 1826727, "The origins and spread of millet cultivation" (PI: X. Liu); the Rae and Edith Bennett Travelling Scholarship (P. J. Jones); the International Center for Energy, Environment and Sustainability (InCEES, PI: X. Liu), Washington University in St Louis; and the European Social Fund, under grant 09.3.3-LMT-K-712 “Improvement of researchers' qualification by implementing world-class R\&D projects" (PI: G. Motuzaite Matuzeviciute) and Darwin College, Cambridge for financial support.

\section{Appendix A.}

Supplementary Table S1

\section{Appendix B.}


Supplementary References

\section{References}

An, T., Pashkevich, G., Jones, M., 2018. Re-examining millet impressions in Usatovo clay materials from NW Black Sea region, Ukraine. Archaeological and Anthropological Sciences, Published online: doi.org/10.1007/s12520-1201810718-12523.

Barton, L., An, C.-B., 2014. An evaluation of competing hypotheses for the early adoption of wheat in East Asia. World Archaeology 46, 775-798.

Bates, J., Petrie, C.A., Singh, R.N., 2016. Approaching rice domestication in South Asia: New evidence from Indus settlements in northern India. Journal of Archaeological Science 78, 193-201.

Bellwood, P., Renfrew, C., 2002. Examining the Farming/language Dispersal Hypothesis. McDonald Institute Monographs, Cambridge.

Bestel, S., Bao, Y., Zhong, H., Chen, X., Liu, L., 2017. Wild plant use and multi-cropping at the early Neolithic Zhuzhai site in the middle Yellow River region, China. The Holocene, published online: doi.org/10.1177/0959683617721328.

Betts, A., Jia, P.W., Dodson, J., 2014. The origins of wheat in China and potential pathways for its introduction: A review. Quaternary International 30, 1-11. Bogaard, A., 2004. Neolithic Farming in Central Europe: An archaeobotanical study of crop husbandry practices. Routledge, London and New York. Boivin, N., Crowther, A., Prendergast, M., Fuller, D.Q., 2014. Indian Ocean food globalisation and Africa. African Archaeological Review 31, 547-581. 
Boivin, N., Fuller, D., 2009a. Shell middens, ships and seeds: explring coastal subsistence, maritime trade and the dispersal of domesticateds in and around the ancient Arabian Peninsula. Journal of World Prehistory 22, 113-180.

Boivin, N., Fuller, D.Q., 2009b. Shell middens, ships and seeds: exploring soastal subsistence, maritime trade and the dispersal of domesticates in and around the ancient Arabian Peninsula. Journal of World Prehistory 22, 113-118.

Boyle, K., Renfrew, C., Levine, M., 2002. Ancient Interactions: East and West in Eurasia. McDonald Institute Monographs, Cambridge.

Braidwood, R.J., Cambel, H., Watson, P.J., 1969. Prehistoric investigations in southeastern Turkey. Science 164, 1275-1276.

Chen, F.-H., Dong, F.-H., Zhang, D.-J., Liu, X.-Y., Jia, X., An, C.-B., Ma, M.-M., Xie, Y.-W., Barton, L., Ren, X.-Y., Zhao, Z.-J., Wu, X.-H., Jones, M.K., 2015. Agriculture facilitated permanent human occupation of the Tibetan Plateau after 3600BP. Science 347, 248-250.

Colledge, S., Conolly, J., 2007. The Origins and Spread of Domestic Plants in Southwest Asia and Europe. Left Coast Press, Walnut Creek, CA.

Crawford, G., Chen, X., Wang, J., 2006. Houli culture rice from the Yuezhuang site, Jinan. Dongfang Kaogu (East Asia Archaeology) 3, 247-251.

Crosby, A.W.J., 2003. The Columbian Exchange: Biological and Cultural Consequences of 1492. Praeger, Westport, CT.

d'Alpoim Guedes, J., Butler, E.E., 2014. Modeling constraints on the spead of agriculture to Southwest China with thermal niche models. Quaternary International 349, 29-41. 
d'Alpoim Guedes, J., Lu, H., Li, Y., Spengler, R.N., Wu, X., Aldenderfer, M.S., 2013. Moving agriculture onto the Tibetan Plateau: the archaeobotanical evidence. Archaeological Anthropological Sciences 6, 255-269.

Dong, G., Yang, Y., Liu, X., Li, H., Cui, Y., Wang, H., Chen, G., Dodson, J., Chen, F., 2017. Prehistoric trans-continental cultural exchange in the Hexi Corridor, northwest China. The Holocene, published online: doi.org/10.1177/0959683617735585. Doumani, P.N., Frachetti, M.D., Beardmore, R., Schmaus, T., Spengler, R.N., Mar'yashev, A.N., 2015. Burial ritual, agriculture, and craft production among Bronze Age pastoralists at Tasbas (Kazakhstan). Archaeological Research in Asia 1$2,17-32$.

Frachetti, M.D., 2012. Multiregional emergence of mobile pastoralism and nonuniform institutional complexity across Eurasia. Current Anthropology 53, 2-38. Frachetti, M.D., Smith, C.E., Traub, C.M., Williams, T., 2017. Nomadic ecology shaped the highland geography of Asia's Silk Roads. Nature 543, 193-198.

Frachetti, M.D., Spengler, R.N., Fritz, G.J., Mar'yashev, A.N., 2010. Earliest direct evidence for broomcorn millet and wheat in the central Eurasia steppe region. Antiquity 84, 993-1010.

Fuller, D.Q., 2006. Agircultural origins and frontiers in South Asia: A working synthesis. Journal of World Prehistory 20, 1-86.

Fuller, D.Q., 2011a. Finding plant domestication in the Indian Subcontinent. Current Anthropology 52, S347-362.

Fuller, D.Q., 2011b. Pathways to Asian civilizations: Tracing the origins and spread of rice and rice cultures. Rice 4, 78-92. 
Fuller, D.Q., Boivin, N., Hoogervorst, T., Allaby, R., 2011a. Across the Indian Ocean: the prehistoric movement of plants and animals. Antiquity 85, 544-558.

Fuller, D.Q., Castillo, C., 2016. Diversification and cultural construction of a crop: the case of rice and waxy cereals in the food cultures of eastern Asia, in: Lee-Thorp, J.A., Katzenberg, M.A. (Eds.), The Oxford Handbook of the Archaeology of Diet. Oxford University Press, Oxford, p. published online:

doi.org/10.1093/oxfordhb/9780199694013.9780199694013.9780199694018.

Fuller, D.Q., Qin, L., Zheng, Y., Zhao, Z., Chen, X., Hosoya, L.A., Sun, G.-P., 2009.

Domestication rate in rice: Spikelet bases from the lower Yangtze. Science 323, $1607-1610$.

Fuller, D.Q., Sato, Y., Castillo, C., Qin, L., Weisskopf, A.R., Kingwell-Banham, E.J., Song, J., Ahn, S.-M., van Etten, J., 2010. Consilience of genetics and archaeobotany in the entangled history of rice. Archaeological and Anthropological Science 2, 115-131. Fuller, D.Q., van Etten, J., Manning, K., Castillo, C., Kingwell-Banham, E., Weisskopf, A., Qin, L., Sato, Y.-I., Hijmans, R.J., 2011b. The contribution of rice agriculture and livestock pastoralism to prehistoric methane levels: An archaeological assessment. The Holocene 21, 743-759.

Gross, B.L., Zhao, Z., 2013. Archaeological and genetic insights into the origins of domesticated rice. Proceedings of National Academy of Science of the United States of America 111, 6190-6197.

Harris, D., 2010. Origins of Agriculture in Western Central Asia. University of Pennsylvania Museum, Philadelphia. 
Held, T., Goldblatt, D., McGrew, A., Perraton, J., 1999. Global Transformations. Polity Press, Cambridge.

Hilbert, L., Góes Neves, E., Pugliese, F., Whitney, B.S., Shock, M., Veasey, E., Zimpel, C.A., Iriarte, J., 2017. Evidence for mid-Holocene rice domestication in the Americas. Nature Ecology and Evolution 1, 1693-1698.

Hunt, H.V., Linden, M.V., Liu, X., Motuzaite-Matuzeviciute, G., Colledge, S., Jones, M.K., 2008. Millets across Eurasia: chronology and context of early records of the genera Panicum and Setaria from archaeological sites in the Old World. Vegetation History and Archaeobotany 17, 5-18.

James, P., 2005. Arguing globalizations: Propositions towards an investigation of global formation. Globalization 2, 193-209.

Jia, X., Dong, G., Li, H., Brunson, K., Chen, F., Ma, M., Wang, H., An, C., Zhang, K., 2012. The development of agriculture and its impact on cultural expansion during the late Neolithic in the Western Loess Plateau, China. the Holocene 23, 85-92.

Jin, G., Yan, D., Liu, C., 2008. Wheat grains are recovered from a Longshan cultural site, Zhaojiazhuang, in Jiaozhou, Shandong Province, Cultural Relics in China. Jones, G., Jones, H., Charles, M.P., Jones, M.K., Colledge, S., Leigh, F.J., Lister, D.L., Smith, L.M.J., Powell, W., Brown, T.A., 2012. Phylogeographic analysis of barley DNA as evidence for the spread of Neolithic agriculture through Europe. Journal of Archaeological Science 39, 3230-3238.

Jones, H., Civán, P., Leigh, J., Smith, F.J., Jones, M.K., Charles, M.P., Molina-Cano, J.L., Powell, W., Jones, G., Brown, T.A., 2011a. Evolutionary history of barley cultivation 
in Europe revealed by genetic analysis of extant landraces. BMC Evolutionary Biology 11, 320.

Jones, H., Lister, D.L., Cai, D.-W., Kneale, C.J., Cockram, J., Peña-Chocarro, L., Jones, M.K., 2016a. The trans-Eurasian crop exchange in prehistory: discerning pathways from barley phylogeography. Quaternary International 426, 26-32.

Jones, M.K., 2004. Between fertile crescents: minor grain crops and agricultural origins, in: Jones, M.K. (Ed.), Traces of Ancestry - Studies in Honour of Colin Renfrew. McDonald Institute Monographs Cambridge, pp. 127-135.

Jones, M.K., Harriet, H., Kneale, C.J., Lightfoot, E., Lister, D., Liu, X.-Y., Motuzaite Matuzeviciute, G., 2016b. Food Globalisation in Prehistory: the agrarian foundation of an interconnected continent. Journal of the British Academy 4, 73-87. Jones, M.K., Hunt, H.V., Lightfoot, E., Lister, D., Liu, X., Motuzaite-Matuziviciute, G., 2011b. Food globalization in prehistory. World Archaeology 43, 665-675. Levitt, T., 1983. The globalization of markets. Harvard Business Review 61, 92-102. Lightfoot, E., Liu, X., Jones, M.K., 2013. Why move starchy cereals? a review of the isotopic evidence for prehistoric millet consumption across Eurasia. World Archaeology 45, 574-623.

Lister, D.L., Jones, H., Oliveira, H.R., Petrie, C.A., Liu, X., Cockram, J., Kneale, C.J., Kovaleva, O., Jones, M.K., 2018. Barley heads east: Genetic analyses reveal routes of spread through diverse Eurasian landscapes. PLOS ONE.

Lister, D.L., Jones, M.K., 2012. Is naked barley an eastern or a western crop? The combined evidence of archaeobotany and genetics. Vegetation History and Archaeobotany 22, 439-446. 
Liu, C., Kong, Z., Lang, S., 2004. Dadiwan yizhi nongye zhiwu yicun yu renlei shengcun huanjing de tantao (Archaeobotanical remains and human ecology at Dadiwan). Zhongyuan Wenwu (Cultural Relics of Central China) 118, 25-29. Liu, X., Fuller, D., Jones, M.K., 2015. Early agriculture in China, in: Barker, G., Goucher, C. (Eds.), The Cambridge World History - Volume II: A world with agriculture, 12,000 BCE-500CE. Cambridge University Press, Cambridge, pp. 310-334. Liu, X., Hunt, H.V., Jones, M.K., 2009. River valleys and foothills: changing archaeological perceptions of north China's earliest farms. Antiquity 83, 82-95. Liu, X., Jones, M.K., 2014. Food globalisation in prehistory: top down or bottom up? Antiquity 88, 956-963.

Liu, X., Lightfoot, E., O'Connell, T.C., Wang, H., Li, S., Zhou, L., Hu, Y., MotuzaiteMatuzeviciute, G., Jones, M.K., 2014. From necessity to choice: dietary revolutions in west China in the second millennium BC. World Archaeology 46, 661-680. Liu, X., Lister, D.L., Zhao, Z., Petrie, C.A., Zeng, X., Jones, P.J., Staff, R., Pokharia, A.K., Bates, J., Singh, R.N., Weber, S.A., Motuzaite Matuzeviviute, G., Dong, G., Li, H., Lü, H., Jiang, H., Wang, J., Ma, J., Tian, D., Jin, G., Zhou, L., Wu, X., Jones, M.K., 2017a. Journey to the East: diverse routes and variable flowering times for wheart and barley en route to prehistoric China. PLOS ONE Published Online, upblished online: doi.org/10.1371/journal.pone.0187405.

Liu, X., Lister, D.L., Zhao, Z.-Z., Staff, R.A., Jones, P.J., Zhou, L.-P., Pokharia, A.K., Petrie, C.A., Pathak, A., Lu, H.-L., Motuzaite Matuzeviciute, G., Bates, J., Pilgram, T.K., Jones, M.J., 2016a. The virtues of small grain size: Potential pathways to a distinguishing feature of Asian wheats. Quaternary International 426, 107-109. 
Liu, X., Margaritis, E., Jones, M.K., 2018a. From the harvest to the meal in prehistoric China and Greece: A comparative approach to the social context of food, in: Lloyd, G., Dong, G., Zhao, J.J. (Eds.), Ancient Greece and China Compared. Cambridge University Press, Cambridge, pp. 355-372.

Liu, X., Motuzaite Matuzeviciute, G., Hunt, H.V., 2018b. From a fertile idea to a fertile arc: The origins of broomcorn millet 15 years on, in: Lightfoot, E., Liu, X., Fuller, D.Q. (Eds.), Far from the Hearth: Essays in Honour of Martin K. Jones. McDonald Institute Conversations, Cambridge, pp. 155-164.

Liu, X., Reid, R.E.B., Lightfoot, E., Motuzaite Matuzeviciute, G., Jones, M.K., 2016b. Radical change and dietary conservatism: Mixing model estimates of human diets along the Inner Asia and China's mountain corridors. the Holocene Published online, published online: doi.org/10.1177/0959683616646842.

Liu, X., Zhao, Z., Jones, M.K., 2017b. From people's commune to household responsibility: Ethnoarchaeological perspectives of millet production in prehistoric northeast China. Archaeological Researach in Asia 11, 51-57.

Long, T., Leipe, C., Jin, G., Wagner, M., Guo, R., Schröder, O., Tarasov, P.E., 2018. The early history of wheat in China from 14C dating and Bayesian chronological modelling. Nature Plants 4, 272-279.

McNally, K.L., Childs, K.L., Bohnert, R., Davidson, R.M., Zhao, K., Ulat, V.J., Celler, G., Clark, R.M., Hoen, D.R., Bureau, T.E., Stokowski, R., Ballinger, D.G., Frazer, K.A., Cox, D.R., Padhukasahasram, B., Bustamante, C.D., Weigel, D., Mackill, D.J., Bruskiewich, R.M., Ratsch, G., Buell, C.R., Leugn, H., Leach, J.E., 2009. Genomewide SNP variation 
reveals relationship among landraces and modern varieties of rice. Proceedings of National Academy of Science of the United States of America 106, 12273-12278. Meadow, R.H., 1996. The origins and spread of agriculture and pastoralism in north western South Asia, in: Harris, D. (Ed.), The Origins and Spread of Agriculture and Pastoralism in Eurasi. UCL Press, London, pp. 390-412.

Mei, J., 2003. Qijia and Seima-Turbino: the question of early contacts between Northwest China and Eurasian Setppe, The Museum of Far Eastern Antiquities Bulletin No. 75. The Museum of Far Eastern Antiquities, Stockholm, pp. 31-55. Miller, N., Spengler, R., Frachetti, M.D., 2016. Millet cultivation across Eurasia: Origins, spread, and the influence of seasonal climate. The Holocene 26, 1566-1575. Motuzaite Matuzeviciute, G., Abdykanova, A., Kume, S., Nishiaki, Y., Tabaldiev, K., 2018. The effect of geographical margins on cereal grain size variation: Case study for highlands of Kyrgyzstan. Journal of Archaeological Science: Reports 20, 400-410. Motuzaite Matuzeviciute, G., Staff, R.A., Hunt, H.V., Liu, X., Jones, M.K., 2013. The early chronology of broomcorn millet (Panicum miliaceum) in Europe. Antiquity 87, 1073-1085

Petrie, C.A., 2015. Mehgarh, Pakistan, in: Barker, G., Goucher, C. (Eds.), The Cambridge World History Volume II - A World with Agriculture, 12000 BCE-500 CE. Cambridge University Press, Cambridge, pp. 289-309.

Pokharia, A.K., Kharakwal, J.S., Srivastava, A., 2014. Archaebotanical evidence of millets in the Indian subcontinent with some observations on their role in the Indus civilization. Journal of Archaeological Science 42, 442-455.

Postgate, J.N., 1984. Introduction. Bulletin on Sumerian Agriculture 1, 1-7. 
Qiu, X., 1989. Gu Wenzi Lunji [Essays on Ancient Text]. Zhonghua Shuju [Chung Hwa Book Co.], Beijing.

Ren, X., Lemoine, X., Mo, D., Kidder, T.R., Guo, Y., Qin, Z., Liu, X., 2016. Foothills and intermountain basins: Does China's Fertile Arc have a 'Hilly Flanks'? Quaternary International 426, 86-96.

Sang, T., Ge, S., 2007. The puzzle of rice domestication. Journal of Integrative Plant Biology 49, 760-768.

Saraswat, K.S., 2004. Plant economy of early farming communities, in: Singh, B.P. (Ed.), Early Farming Communities of the Kaimur (Excavations at Senuwar). Publication Scheme, Jaipur, pp. 416-535.

Sergusheva, E.A., 2006. Seeds and fruits from late Neolithic site Rettichovka Geologitcheskaya of Primorye region, in: Hiroki, O. (Ed.), Cultivated Cereals in Prehistoric and Ancient Far East Asia 2. Shimoda Print, Kumamoto, pp. 1-11. Sherratt, A., 2006. The Trans-Eurasian exchange: the prehistory of Chinese relations with the West, in: Mair, V. (Ed.), Contact and Exchange in the Ancient World. Hawaii University Press, Honolulu, pp. 30-61.

Sherratt, A.G., 2005. The Origins of Farming in South-West Asia, ArchAtlas. Available at: http://www.archatlas.org/OriginsFarming/Farming.php. Accessed on 11 Dec 2018. Spengler, R., Frachetti, M., Doumani, P., Rouse, L., Cerasetti, B., Bullion, E., Mar'yashev, A., 2014. Early agriculture and crop transmission among Bronze Age mobile pastoralists of Central Eurasia. Proceedings of the Royal Society B: Biological Sciences 281, 1-7. 
Spengler, R., Ryabogina, N., Tarasov, P.E., Wagner, M., 2016. The spread of agriculture into northern Central Asia: Timing, pathways, and environmental feedbacks. The Holocene 26, 1527-1540.

Spengler , R.N., 2015. Agriculture in the Central Asian Bronze Age. Journal of World Prehistory 28, 215-253.

Steger, M.B., James, P., 2013. Levels of subjective globalization: Ideologies, imaginareies, ontologies. Perspectives on Global Development and Technology 12, $1-2$.

Stevens, C.J., Murphy, C., Roberts, R., Lucas, L., Silva, F., Fuller, D.Q., 2016. Between China and South Asia: A middle Asian corridor of crop dispersal and agricultural innovation in the Bronze Age. The Holocene, published online: doi.org/10.1177/0959683616650268.

Tewari, R., Srivastava, R.K., Saraswat, K.S., Singh, I.B., Singh, K.K., 2008. Early farming at Lahuradewa. Pragdhara 18, 347-373.

Tsang, Z., 2012. Issues relating to the ancient rice and millet grains unearthed from the archaeological sites in Tainan Science Park. Journal of Chinese Dietary Culture 8, 1-24.

Valamoti, S.M., 2013. Millet, the late comer: on the tracks of Panicum miliaceum in prehistoric Greece. Archaeological and Anthropological Sciences, Published online, DOI $10.1007 / s 12520-12013-10152-12525$.

van der Veen, M., 2010. Agricultural innovation: invention and adoption or change and adaptation? World Archaeology 42, 1-12. 
Vaughan, D.A., Lu, B., Tomooka, N., 2008. The evolving story of rice evolution. Plant Science 174, 394-408.

Vita-Finzi, C., 1969. Geological opportunism, in: Ucko, P.J., Dimbleby, G. (Eds.), The domestication and exploitation of plants and animals. Duckworth, London, pp. 3134.

Waetzoldt, H., 1985. Ölpflanzen und Pflanzenöle im 3. Jahrtausend.

Bulletin on Sumerian Agriculture 5, 77-96.

Watson, A.M., 1983. Agricultural Innovation in the Early Islamic World. Cambridge University Press, Cambridge.

Weber, S., 1998. Out of Africa: the initial impact of millets in South Asia. Current Anthropology 39, 267-282.

Weber, S.A., 1999. Seeds of urbanism: palaeoethnobotany and the Indus Civilization. Antiquity 73, 813-826.

Weber, S.A., 2003. Archaeobotany at Harappa: Indications for Change, in: Weber, S., Belcher, B. (Eds.), Indus Ethnobiology: New Perspectives from the Field. Lexington Books, pp. 175-198.

Weber, S.A., Lehman, H., Barela, T., Hawks, S., Harriman, D., 2010. Rice or millets: early farming strategies in prehistoric central Thailand. Archaeological and Anthropological Science 2, 79-88.

Wilkinson, T.C., Sherratt, S., Bennet, J., 2011. Interweaving Worlds: Systemic Interactions in Eurasia, 7th to the 1st Millennia BC. Oxbow Books, Oxford. 
Willcox, G., 1991. Carbonised plant remains from Shortughai, Gafhanistan, in:

Renfrew, J.M. (Ed.), New Light on Early Farming - Recent Developments in Palaeoethnobotany. Edinburgh University Press, Edinburgh, pp. 139-152.

Winchell, F., Stevens, C.J., Murphy, C., Champion, L., Fuller, D.Q., 2017. Evidence for sorghum domestication in fourth millennium BC eastern Sudan. Current Anthropology 58, 673-683.

Yang, X., Wan, Z., Perry, L., Lu, H., Wang, Q., Zhao, C., Li, J., Xie, F., Yu, J., Cui, T., Wang, T., Li, M., Ge, Q., 2012. Early millet use in northern China. Proc.Natl. Acad. Sci. U.S.A. 109, 3726-3730.

Yu, J., Wang, Y., He, J., Feng, Y., Li, Y., Li, W., 2018. Xinjiang Jimunai Xian

Tongtiandong Yizhi (Tongtiandong at Jimunai county, Xinjiang). Kaogu (Archaeology) 610, 723-734.

Zhao, Z., 2009. Eastward spread of wheat into China - new data and new issues, in: Liu, Q., Bai, Y. (Eds.), Chinese Archaeology - Volume Nine. China Social Press, Beijing, pp. 1-9.

Zhao, Z., 2010a. New data and new issues for the study of origin of rice agriculture in China. Archaeological and Anthropological Science 2, 99-105.

Zhao, Z., 2010b. New data and new issues from the study of origin of rice agriculture in China. Archaeological and Anthropological Science 2, 99-105.

Zhao, Z., 2010c. Paleoethnobotany: Theories, Methods and Practice. Academy Press, Beijing.

Zhao, Z., 2011. New archaeobotanic data for the study of the origins of agriculture in China. Current Anthropology 52, S295-S304. 
Zhao, Z., Chen, J., 2011. Sichuan Maoxian Yingpanshan yizhi fuxuan jieguo ji fenxi (Results of flotation of Yingpanshan site, Maoxian, Sichuan Province). Nanfang Wenwu (Southern Cultural Relics), 60-67.

Zohary, D., Hopf, M., Weiss, E., 2012. Domestication of Plants in the Old World (Fourth Edition). Clarendon Press, Oxford. 